\title{
Semen quality in welders exposed to radiant heat
}

\author{
Jens Peter Bonde
}

\begin{abstract}
Several studies suggest that welding is detrimental to the male reproductive system. Welding fume and radiant heat are of interest as possible causal factors. This study investigates semen quality and sex hormone concentrations among 17 manual metal arc alloyed steel welders with a moderate exposure to radiant heat (globe temperature ranging from $31 \cdot 1^{\circ}$ to $44 \cdot 8^{\circ} \mathrm{C}$ ), but without substantial exposure to welding fume toxicants. During exposure to heat the skin temperature in the groin increased on average by $1.4^{\circ} \mathrm{C}$ $\left(\mathrm{SE} \pm 0.72^{\circ} \mathrm{C}\right)$. Sperm count and motile sperm count were non-significantly reduced among welders in comparison with two different reference groups. Within the group of welders the proportion of sperm with normal shape declined significantly after six weeks of exposure to heat and increased after a break in exposure. Sperm count and sperm concentration had the same pattern of intraindividual change in relation to exposure to radiant heat, but the changes were not statistically significant. No consistent changes in concentrations of sex hormones were found. The welders investigated were more exposed to radiant heat than welders in general. The results suggest that the study group of welders experienced a reversible decrease in semen quality, most likely caused by a moderate exposure to radiant heat (about five hours a day through several weeks). It remains to be established if even lower levels of exposure to radiant heat in the general population of welders has any impact on semen quality and fertility.
\end{abstract}

Several Danish studies suggest that welding work is detrimental to the male reproductive system, ${ }^{1-5}$ but these findings have not been confirmed by other studies. $^{6-8}$ If real the magnitude of risk of reduced reproductive performance in terms of reduced semen quality, delayed conception, and reduced fertility appears to be small (odds ratio ranging from $1 \cdot 1$ to

Department of Occupational Medicine, Hospital of Aalborg, Denmark

$\mathrm{J} P$ Bonde
$2 \cdot 0)$. In accord with this only moderate deterioration (averaging 10-25\%) in semen quality has been encountered among mild steel welders.

Several types of exposures associated with welding may represent a hazard to the male reproductive system. As well as water soluble toxic substances in welding fume particulates, raising the temperature of the testes might be of significance. Animal studies and experimental studies on human subjects exposed to short term, heavy local, or systemic heat strain have established heat as a potent suppressor of spermatogenesis. ${ }^{9-13}$ The threshold of long term exposure to radiant heat for impairment of spermatogenesis is, however, unknown. In fact, it has been disputed whether heat exposure in the occupational environment is associated with any significant impairment of male reproductive function. ${ }^{14}$

This study takes advantage of an opportunity to investigate a group of welders with long term moderate exposure to radiant heat without any substantial exposure to welding fume toxicants. The purpose was to examine whether exposure to radiant heat at magnitudes occurring among welders affects semen quality. Welders selected for this study undoubtedly have a higher exposure to radiant heat than welders in general. Accordingly, a positive result would encourage investigation of the "heat hypothesis" in further studies aimed at identifying reproductive risk factors among male welders, whereas a negative result would practically rule out a role for exposure to radiant heat.

Semen quality was examined before, during, and after exposure to radiant heat. This longitudinal design in which each person acted as his own control was chosen to overcome obvious methodological drawbacks associated with a cross sectional design. Nevertheless, semen quality of heat exposed welders was also compared with two reference groups investigated by the same methods in previous sperm studies.

\section{Subjects and methods}

EXPOSURE, SELECTION OF PARTICIPANTS, AND SEMEN SAMPLING

The study was undertaken at a plant which manufactures boilers for power stations. Welding of sockets on headers in chromium alloyed steel (X-20 CRMDV-121; 10-12.5\% and $0.3-0.8 \%$ content of chromium and nickel respectively) was performed by 


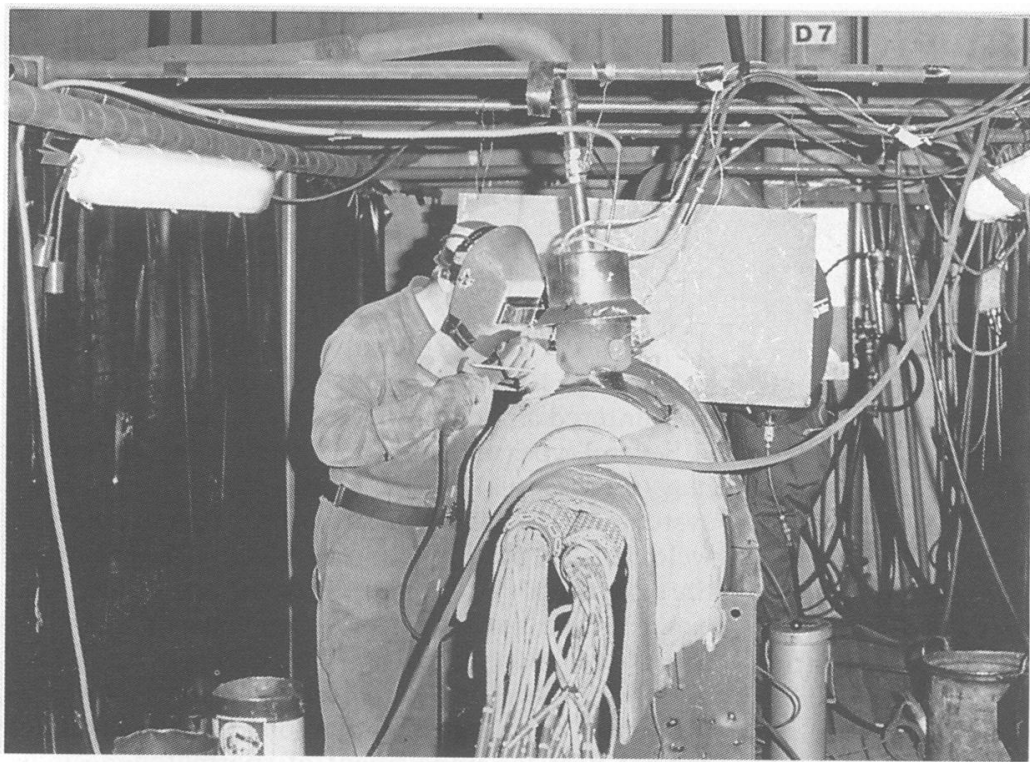

Figure 1 Welding of sockets on headers preheated to $240^{\circ} \mathrm{C}$ with $M M A$ welding method. Notice local exhaust ventilation, use of compressed air respirator, and insulating mats.

a team of specialised welders. All welders employed in this particular job at 1 December 1988 and a group of welders transferred to the team in November 1989 were asked to participate. Seventeen of 20 welders agreed to take part.

The sockets were welded in an upright position by the manual metal arc (MMA) welding method (fig 1). Local exhaust ventilation adopted to this particular welding job and compressed air respirators were used. The entire header and the electrode rods were heated to $240^{\circ} \mathrm{C}$. Insulating mats protected the workers, in particular the upper part of the body, against exposure to radiant heat (see fig 1).

Skin temperature was monitored through a workshift by a two channel digital Memolog instrument in nine welders and five fitters doing light physical work. One temperature probe was placed proximally in the right trigonum scarpae and the other at the dorsum between scapulae. The skin temperature was recorded every minute and the welders recorded the periods of welding throughout the workshift.

Chromium concentrations in spot urine samples taken before (second void in the morning) and after a day shift were determined by Zeeman atomic absorption spectrometry at the Danish National Institute of Occupational Health. ${ }^{15}$ All participants were carefully instructed to avoid contamination. Chromium concentrations were adjusted to creatinine concentrations.

Occupational and medical histories were gathered by interviews. Figure 2 shows the schedule for collecting semen specimens. Samples were collected by masturbation after preferably three days of abstinence. All samples were analysed blindly within three

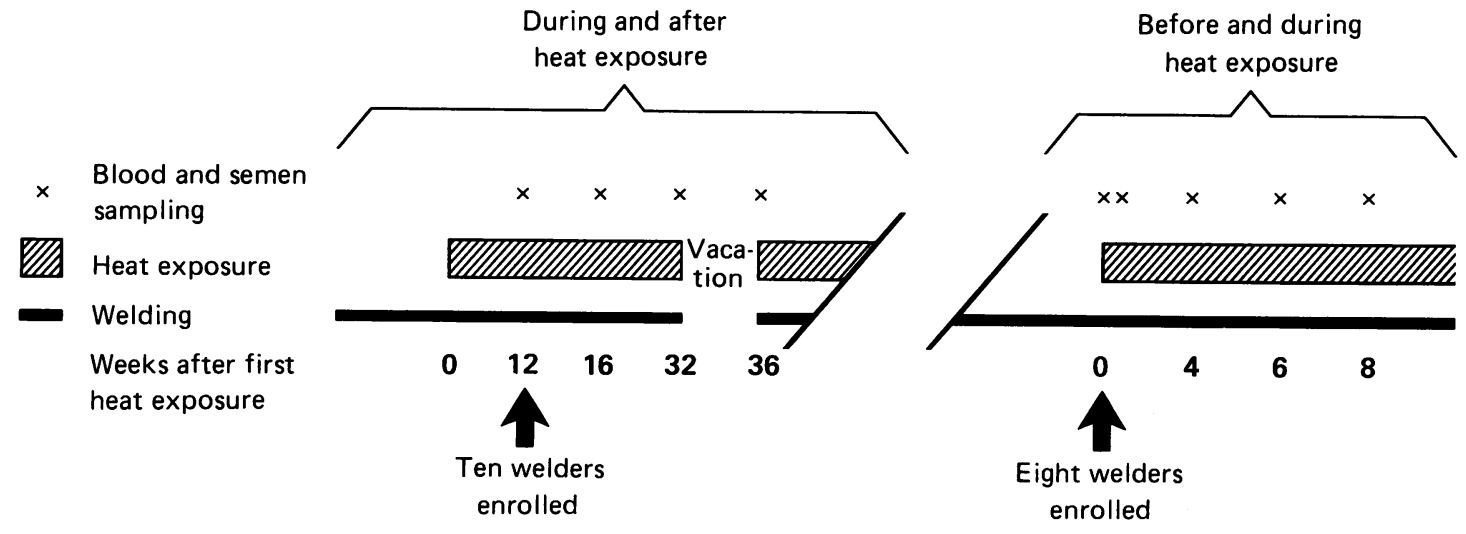

Figure 2 Schedule for blood and semen sampling. 
hours of collection in accordance with World Health Organisation guidelines for the examination of human semen. ${ }^{16}$ The total motile sperm count was obtained by computing the product of total sperm count and proportion of motile sperm. Blood samples were collected by venepuncture at 7.00 am on the days of semen collection. Serum concentrations of testosterone, follicle stimulating hormone (FSH), and luteinising hormone $(\mathrm{LH})$ were determined by radioimmunoassay.

\section{REFERENCE GROUPS AND ANALYSIS \\ Cross sectional design}

Semen quality of participants was compared with two reference groups. The first group comprised 54 non-welding metalworkers enrolled in a previous study. ${ }^{5}$ The participation rate in this study was low $(37 \%)$, and an excess of non-welding metalworkers with reduced semen quality had been selected. ${ }^{5}$ The second group was an unselected cohort of 19 flexoprinters (participation rate $90.5 \%$ ) with a very low exposure to organic solvents not considered toxic to the reproductive system. ${ }^{17}$ The subjects in both reference groups delivered three semen samples at monthly intervals. These were examined blindly in the same laboratory in accord with the same protocol. Mean values of semen parameters were computed for each person and differences between welders and the pooled reference group were tested by the MannWhitney U test. ${ }^{18}$

\section{Longitudinal design}

Within the group of welders the effect of heat exposure was analysed by paired comparison of semen quality in the first two weeks, four to eight weeks, and 12 to 32 weeks of exposure, and immediately after a four week summer holiday (paired $t$ test $^{18}$ ).

\section{Results}

The globe temperature at a distance of $20 \mathrm{~cm}$ from the header ranged from $31 \cdot 1^{\circ} \mathrm{C}$ to $44 \cdot 8^{\circ} \mathrm{C}$ and the dry bulb temperature at the same location ranged from $20 \cdot 2^{\circ} \mathrm{C}$ to $22 \cdot 0^{\circ} \mathrm{C}$. Measurements of skin temperature during a workshift showed average temperature increases of $1.4(\mathrm{SE} \pm 0.72)^{\circ} \mathrm{C}$ in the groin and 3.0 $(\mathrm{SE} \pm 1.34)^{\circ} \mathrm{C}$ on the back during periods of exposure to radiant heat. These figures were obtained by calculating the paired differences of average temperature measurements recorded with and without exposure to heat. Figure 3 shows that several minutes elapsed before a steady state for skin temperature was reached.

Chromium concentrations in preshift urine samples of the welders were slightly increased in comparison with metal workers (table). Furthermore, despite local exhaust ventilation and use of compressed air respirators, postshift urine

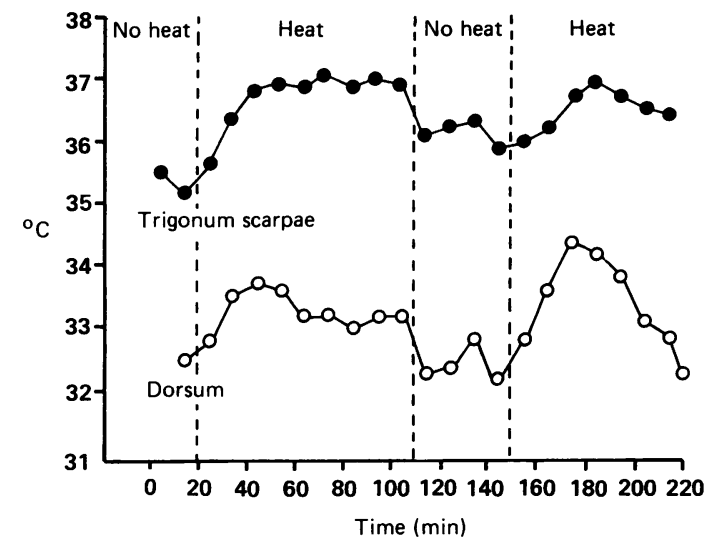

Figure 3 Skin temperature at groin (trigonum scarpae) and back (dorsum, between scapulae) during part of a workshift. Results of measurements in one welder. Each point represents mean of temperature recordings through 10 minutes.

chromium concentrations increased by twofold the preshift level on the same day. The average paired increase was $1.18 \mu \mathrm{mol}$ chromium $/ \mathrm{mmol}$ creatinine $(\mathrm{p}<0.01)$ or $13.7 \mu \mathrm{mol}$ chromium $/ 1(\mathrm{p}<0.05)$.

The table gives the comparison of semen quality between welders, non-welding metalworkers, and flexoprinters. Mean values of semen parameters were computed for each subject. Among welders only semen samples delivered during exposure to heat were included. The group mean of sperm counts approached a significant reduction in welders in comparison with reference groups-even after adjustment for an abstinence period. Exclusion of samples with recorded spillage did not change the result.

Effects of radiant heat on semen quality were also evaluated by within group analysis. Sperm count, motile sperm count, sperm concentration, and proportion of normal shaped sperm decreased within four to six weeks of the beginning of exposure to heat in a subgroup of 10 welders and increased four weeks after cessation of heat exposure in a subgroup of eight welders (fig 4). A significant difference in the proportion of sperm with normal shape $(p<0.01)$ was found between start of exposure (within two weeks) and during exposure values (four to eight weeks), or during exposure (12 to 32 weeks) and after vacation values. Changes in count parameters were insignificant. Other semen parameters and serum concentrations of sex hormones did not show any consistent patterns of change.

\section{Discussion}

Welders selected for this study were undoubtedly more exposed to radiant heat than welders in general. 
Characteristics, exposure, and semen quality in 17 welders, 54 non-welding metalworkers, and 19 flexoprinters

\begin{tabular}{|c|c|c|c|c|}
\hline & $\begin{array}{l}\text { Welders } \\
(n=17)\end{array}$ & $\begin{array}{l}\text { Metalworkers } \\
(n=54)\end{array}$ & $\begin{array}{l}\text { Flexoprinters } \\
(n=19)\end{array}$ & $p$ Value \\
\hline Participation rate $(\%)$ & $85 \cdot 0$ & $36 \cdot 7$ & $90 \cdot 5$ & - \\
\hline $\begin{array}{l}\text { Characteristics: } \\
\text { Age in years (mean (SD)) } \\
\text { Smokers }(\%)\end{array}$ & $\begin{array}{l}35.9(6 \cdot 2) \\
58.8\end{array}$ & $\begin{array}{l}35 \cdot 5(8 \cdot 7) \\
48 \cdot 2\end{array}$ & $\begin{array}{l}36 \cdot 2(6 \cdot 6) \\
79 \cdot 0\end{array}$ & 二 \\
\hline $\begin{array}{l}\text { Alcoholic beverages: } \\
>10 \text { drinks a week }(\%) \\
\text { Days of abstinence period (mean (SD)) } \\
\text { Hours from semen sample collection to analysis (mean (SD)) }\end{array}$ & $\begin{array}{l}29 \cdot 4 \\
3 \cdot 8(1 \cdot 7) \\
1 \cdot 5(0 \cdot 3)\end{array}$ & $\begin{array}{l}13 \cdot 8 \\
4 \cdot 0(2 \cdot 1) \\
2 \cdot 4(0 \cdot 4)\end{array}$ & $\begin{array}{l}52 \cdot 6 \\
4.3(1 \cdot 7) \\
1 \cdot 7(0 \cdot 5)\end{array}$ & $\begin{array}{l}\overline{N S} \\
<0.01\end{array}$ \\
\hline $\begin{array}{l}\text { Urinary chromium concentration ( } \mu \mathrm{mol} / \mathrm{mmol} \text { creatinine): } \\
\text { Before workshift (mean (SD)) } \\
\text { After workshift (mean (SD)) }\end{array}$ & $\begin{array}{l}1.8(1.1) \\
3.0(1.5)\end{array}$ & $\begin{array}{l}0.9(0.6) \\
0.9(0 \cdot 6)\end{array}$ & - & $\begin{array}{l}<0.01 \\
<0.01\end{array}$ \\
\hline $\begin{array}{l}\text { Semen parameters: } \\
\text { Total sperm count (millions; mean (SD)) } \\
\text { Total motile sperm count (millions; mean (SD)) } \\
\text { Sperm concentration (millions/ml; mean (SD)) } \\
\text { Proportion with normal morphology }(\% \text {; mean (SD)) } \\
\text { Proportion motile }(\% \text {; mean }(\mathrm{SD}))\end{array}$ & $\begin{array}{l}141 \cdot 3(100 \cdot 0) \\
81 \cdot 2(60 \cdot 3) \\
53 \cdot 8(23 \cdot 6) \\
60 \cdot 7(12 \cdot 9) \\
57 \cdot 9(11 \cdot 4)\end{array}$ & $\begin{array}{l}186 \cdot 5(109 \cdot 2) \\
114 \cdot 3(73 \cdot 6) \\
58 \cdot 6(23 \cdot 9) \\
66 \cdot 7(17 \cdot 1) \\
57 \cdot 7(14 \cdot 8)\end{array}$ & $\begin{array}{l}194 \cdot 4(119 \cdot 0) \\
112 \cdot 1(113 \cdot 4) \\
76 \cdot 0(48 \cdot 1) \\
63 \cdot 5(10 \cdot 3) \\
56 \cdot 5(8 \cdot 3)\end{array}$ & $\begin{array}{l}\text { 0.056 } \\
\text { NS } \\
\text { NS } \\
\text { NS } \\
\text { NS }\end{array}$ \\
\hline $\begin{array}{l}\text { Hormones: } \\
\text { Testosterone (nmol/1; mean (SD)) } \\
\text { FSH (IU/l; mean (SD)) } \\
\text { LH (IU/l; mean (SD)) }\end{array}$ & $\begin{array}{r}18 \cdot 4(6 \cdot 0) \\
4 \cdot 6(3 \cdot 7) \\
5 \cdot 1(2 \cdot 2)\end{array}$ & $\begin{array}{r}21 \cdot 2(8 \cdot 0) \\
4 \cdot 9(2 \cdot 8) \\
7 \cdot 2(2 \cdot 7)\end{array}$ & $\begin{array}{l}3.3(1.4) \\
5.0(1.9)\end{array}$ & $\begin{array}{l}\text { NS } \\
\text { NS } \\
<0.05\end{array}$ \\
\hline
\end{tabular}

*Welders $v$ referents (metalworkers and printers pooled). Mann-Whitney $U$ test of group difference between mean values of semen parameters and sex hormones. NS $=$ Non-significant.

This selection of participants was aimed to achieve the highest possible exposure to heat to study effects on spermatogenesis in the occupational environment of welders. Obviously the results cannot be generalised to the entire population of welders.

A previous study found an inverse exposure-response relation between exposure to welding fumes and semen quality, suggesting that toxic substances in welding fumes have effects. ${ }^{5}$ As welding of chromium alloys with the MMA method generates a high emission of fume particulates containing hexavalent chromium, ${ }^{19}$ exposure to chromium might have been a confounding factor. Welders in this study were well protected against inhalation of toxic substances, however, by local exhaust ventilation and compressed air respirators, and uptake of chromium during a workshift was so low that the role of chromium in the deterioration of semen quality could be discarded. ${ }^{6}$ This may indicate that moderate exposure to radiant heat affected the semen quality of welders. Sperm count was significantly reduced in comparison with non-welding metalworkers or printers. Within the group of welders, the proportion of normal shaped sperm decreased within six weeks after the onset of exposure and increased during four weeks of vacation. Count parameters showed the same pattern of change, but the associations were not statistically significant. The number of welders investigated was small and variation in semen parameters between and within individual subjects was large; therefore the study had poor statistical power.
Nevertheless the consistency of the findings of the cross sectional analysis and the longitudinal analysis suggest that the deterioration of semen quality found is real and related to exposure. The depression of semen parameters within six weeks after initial heat exposure is in accord with results obtained in experimental short term studies applying intense exposure to heat. ${ }^{101213}$

It was not within the practical possibilities of a field study such as this to obtain a direct measure of the intratesticular temperature, but the rise in skin temperature indicates the extent of heat load. It can be argued that exposure to radiant heat rather than the physical workload was responsible for the increase because the average variation of skin temperature was higher in welders than in fitters performing assembly work (average variance of groin skin temperature $0.73^{\circ} \mathrm{C}$ among welders and $0.21^{\circ} \mathrm{C}$ among fitters). According to one study, however, exercise does not influence semen quality ${ }^{20}$

In conclusion, the results of this study suggest that long term moderate exposure to radiant heat (globe temperature at working distance $30-45^{\circ} \mathrm{C}$ associated with an average of $1.4^{\circ} \mathrm{C}$ increase in groin skin temperature) is associated with a reversible decrease of semen quality.

This study was supported by a grant from the Danish Medical Research Foundation (SLF 12-8864). Susanne Winther from the Department of Occupational Medicine in Aalborg is gratefully ac- 

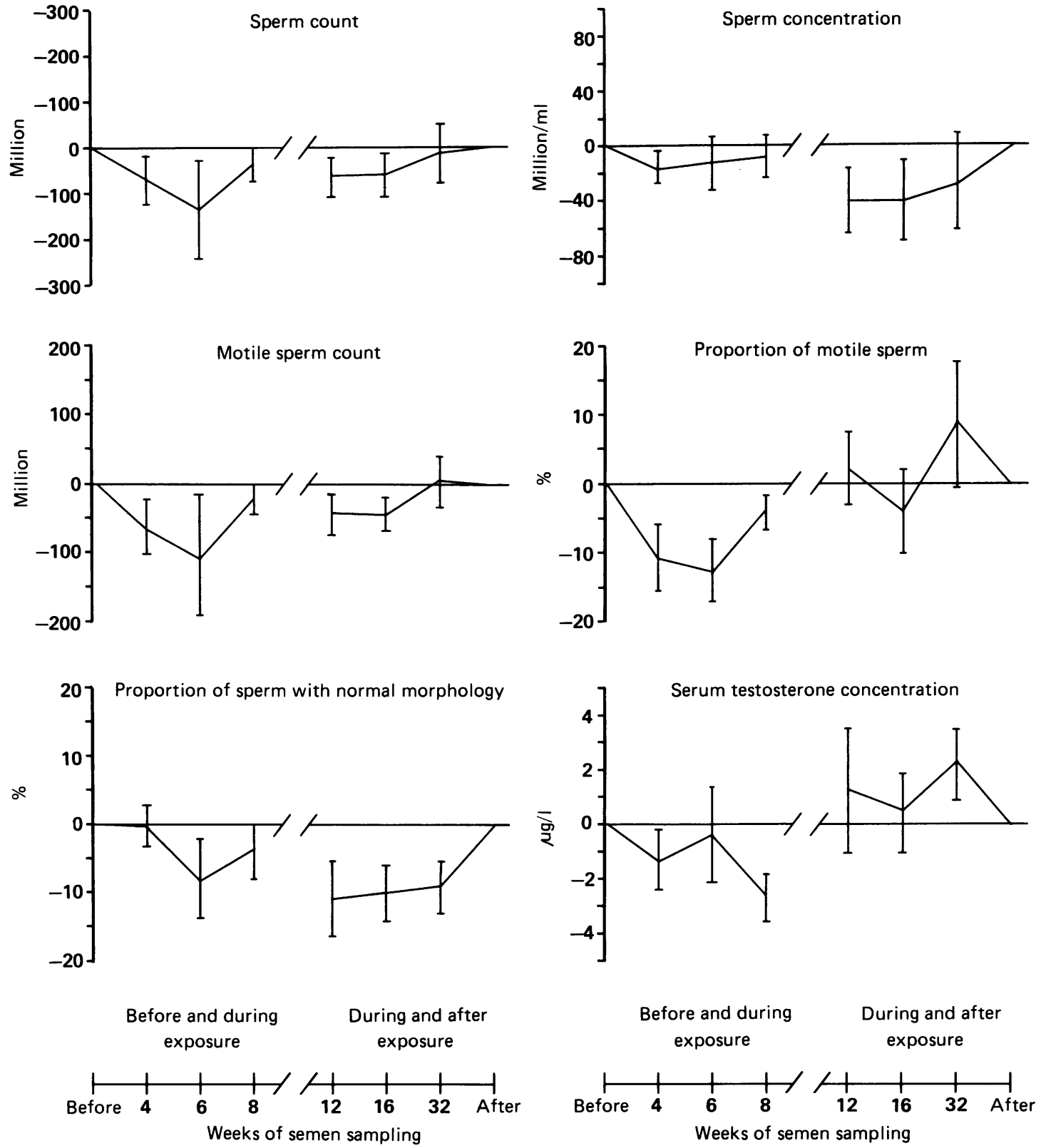

Figure 4 Paired changes in semen quality during radiant heat exposure relative to before exposure value (eight welders, left part of figures) and after exposure value (10 welders, right part of figures) respectively. Paired group mean $\pm S E$.

knowledged for her skilful coordination of the investigation and collection of samples.

Requests for reprints to: Jens Peter Bonde, MD, Department of Occupational Medicine, University Hospital of Aarhus, Nørrebrogade 37-39, 8000 Aarhus, Denmark. 
5 Bonde JP. Semen quality and sex hormones among mild steel and stainless steel welders: a cross sectional study. $\mathrm{Br} J$ Ind Med 1990;47:508-14.

6 Jelnes JE, Knudsen L. Stainless steel welding and semen quality. Reproductive Toxicology 1988;2:209-12.

7 Kandracova E. Fertility disorders in welders. Ceskoslovenska Dermatologika 1981;56:342-5.

8 Bonde JP. Semen quality among welders at follow up after three weeks of non-exposure. Br J Ind Med 1990;47:515-8.

9 Chowdhury AK, Steinberger E. Changes in the germinal epithelium of the rat testis following exposure to heat. $J$ Reprod Fertil 1970;22:205-12.

10 Procope B-J. Effect of repeated increase of body temperature on human sperm cells. Int J Fertil 1965;10:333-9.

11 Brown-Woodman PD, Post EJ, Gass GC, White IG. The effect on a single sauna exposure on spermatozoa. Arch Androl 1984;12:9-15.

12 Robinson D, Rock J, Menkin MF. Control of human spermatogenesis intrascrotal temperature. JAMA 1968;204:290-7.

13 Rock J, Robinson D. Effect of induced intrascrotal hyperthermia on testicular function in man. Am J Obstet Gynecol 1965;93: 793-801.

14 Council on Scientific Affairs. Effects of physical forces on the reproductive cycle. $J A M A$ 1984;251:247-50.
15 Christensen JM, Petersen LM. Enzymatic digestion of whole blood for improved determination of cadmium, nickel and chromium by electrothermal atomic absorption spectrophotometry measurement in rheumatoid arthritis and norma humans. Acta Pharmacologica 1986;59:399-402.

16 Belsey MA. In: Eliasson R, Gallegos AJ, Moghissi KS, Paulsen CA, Prasad MRN eds. World Health Organisation. Laboratory manual for the examination of human semen and semen-cervical mucus interaction. Singapore: WHO Press Concern, 1980.

17 Bonde JP, Mortensen JT, Johansen JP. Toxisk encefalopati og sædkvalitet blandt flexotrykkere [Toxic encephalopathy and semen quality among flexo printers.] Ugeskr Lag 1987;7: 469-71. [In Danish.]

18 SAS Institute Inc. SAS user's guide: statistics, version 5. Cary NC: SAS Institute Inc, 1986.

19 Stern RM. Process-dependent risk of delayed health effects for welders. Environ Health Perspect 1981;41:235-53.

20 McConnell TR, Sinning WE. Exercise and temperature effects on human sperm production and testosterone levels. $\mathrm{Med} \mathrm{Sci}$ Sports Exerc 1984;16:51-5.

Accepted 29 April 1991

\section{Destruction of manuscripts}

From 1 July 1985 articles submitted for publication will not be returned. Authors whose papers are rejected will be advised of the decision and the manuscripts will be kept under security for three months to deal with any inquiries and then destroyed. 